REVIEW

\title{
Meeting the non-clinical education and training needs of new consultants
}

\author{
R Higgins, D Gallen, S Whiteman
}

Postgrad Med J 2005;81:519-523. doi: 10.1136/pgmj.2004.028902

This review highlights the non-clinical training needs of new consultants, identifying strategies for meeting these needs. Non-clinical activities are integral to the consultant's role and senior clinicians need training in these areas. Concerns over the quantity and quality of current provision are compounded by changes the European Working Time Directive and Modernising Medical Careers initiative will bring. Accelerated progression to senior level and reduction in time for training suggest a pressing need to respond to the needs of new consultants. Ad hoc initiatives in a range of healthcare contexts offer examples of how training needs may be met, including mentoring and continuing professional development schemes. A multiprofessional strategy, incorporating elements of higher professional education in general practice and other NHS initiatives (particularly management/leadership training), may offer an appropriate framework within which to capitalise on existing opportunities. There are, however, resource implications that need to be addressed.

See end of article for authors' affiliations

Correspondence to: Dr R Higgins, LNR Postgraduate Deanery, Lakeside House, 4 Smith Way, Grove Park, Leicester LE19 1SS, UK; richard.higgins@ Inrdeanery.nhs.uk

Submitted

20 September 2004

Accepted 28 October 2004
$\mathrm{T}$ his article reviews the current provision of non-clinical skills training for new consultants, both before and after appointment, and identifies possible strategies to meet their education and training needs. Consultants have contractual obligations, which extend beyond their clinical workload and include non-clinical duties such as teaching and management. Their role has also been recognised as involving mentoring skills and as requiring leadership qualities. ${ }^{1}$ Modernising Medical Careers (see http:// www.mmc.nhs.uk) emphasises the acquisition of generic competencies, both clinical and nonclinical. ${ }^{2}$ At the same time, this initiative will, in some specialties, entail an accelerated progression to senior level, placing increasing pressure on available time in which to attain the necessary standards.

A shortening of the duration of specialist training is likely to compound existing concerns over the quality of education and training opportunities. $^{3}$ A number of studies have disclosed anxieties among clinical tutors and specialist registrars (SpRs) over the quality of SpR training in terms of both clinical and nonclinical skills. ${ }^{4-7}$ In particular, there have been complaints that the training is too rigid, too narrow, and too inflexible to address individual interests and non-clinical skills, focusing only on core content. ${ }^{6}$ These complaints have been accompanied by fears that higher specialist training does not provide adequate preparation for a consultant post. ${ }^{6}$ There is therefore a pressing need for training to address non-clinical areas.

There are parallels with general practice training. GP registrars have expressed similar concerns about preparedness for the job after completing the vocational training scheme (VTS), ${ }^{8}$ with the importance of developing management and other non-clinical skills highlighted. The introduction of higher professional education (HPE) sought to redress this shortfall by repeatedly allowing each newly qualified GP to access 20 days of education during the first 12 months after completion of the VTS (facilitated by locum payments and a small educational grant). ${ }^{9}$ This has enabled newly qualified GPs to address their specific educational needs in a relevant working environment. ${ }^{10}$

It may be necessary to establish a robust training programme for new consultants along the lines of the HPE model to address both existing concerns over the teaching of nonclinical skills and the shortcomings of the new accelerated training path to the consultant grade. Alternatively, the medical profession could consider training and development methods adopted in other healthcare contexts.

\section{CURRENT PROVISION}

The quality of quantity of non-clinical training

Concerns over the quality and quantity of postgraduate medical training, particularly in the domain of non-clinical skills, reflects a mismatch between the skills doctors declare they need and those skills their training currently enables them to develop. Many doctors consider non-clinical skills crucial for effective practice. A UK study looking at postgraduate medical education and training drew on the experiences and the insight of SpRs to develop a model of the ideal hospital doctor. ${ }^{11}$ The SpRs participating in the study identified a number of key areas relating to the attributes and skills of an effective practitioner. Included in these areas were generic skills (such as "critical analysis" and communication), change management, and the

\footnotetext{
Abbreviations: EWTD, European Working Time Directive; MMC, Modernising Medical Careers; CPD, continuing professional development; HPE, higher professional education; SpR, specialist registrar; VTS, vocational training scheme; $\mathrm{SHO}$, senior house officer; PDP, professional development plan
} 
application of strategic organisational and career planning. ${ }^{1}$ Yet, historically, higher specialist training has neglected nonclinical skills. Moreover, deficiencies in non-clinical training seem to persist at consultant grade. Gibson and Campbell point to the need for doctors to take an active role in the education and training of medical students and other doctors. ${ }^{12}$ The authors administered a questionnaire to 869 consultants across Northern Ireland. This showed that only $34 \%$ of respondents had received teacher training despite focus groups with some of the respondents showing a strong desire for training in appraisal, assessment, giving feedback to trainees, small group teaching, and problem based learning. ${ }^{12}$

While a number of studies have highlighted doctors' concerns over adequacy of training in a range of areas, a dominant concern relates to training in management skills. Hooke argues that, "in this day and age, most consultants ... have to become involved in management". ${ }^{13}$ Yet, while lead clinicians may feel clinically confident, they often consider themselves far less adept when it comes to management. ${ }^{14} \mathrm{~A}$ UK survey of newly appointed old age psychiatry consultants sought opinions on the adequacy of higher specialist training and the role of the consultant. Questionnaire responses from 35 consultants (a response rate of $81 \%$ ) showed that while general clinical aspects of training were rated as good, training in a number of non-clinical areas was rated as poor, with management experience particularly felt to be lacking. ${ }^{15}$ Another UK survey of new consultant psychiatrists reflecting on their SpR training also showed dissatisfaction with management training. Twenty six consultants (a 92\% response rate) completed a questionnaire rating the quality of their SpR training against a number of items on a five point scale. After their SpR training, mean group scores showed that in terms of both personal and general management skills, respondents felt "poorly" to "moderately" prepared. ${ }^{7}$

Acknowledgement of the need for acquisition of generic competencies is reflected in Managing for excellence in the NHS ${ }^{16}$ and also in the establishment of the NHS Leadership centre (see http://www.modern.nhs.uk). The former promotes the concept of multi-professional leadership and management to deliver high quality health care for the benefit of patients, while the latter aims to develop senior leaders within the NHS to align the challenges of reform and the service improvement agenda. However, managerial training at the level of SHO and above still seems to be inadequate. Management training courses tend to be offered by deaneries in the UK to SpRs at the end of their specialist training ${ }^{17}$ as an "add on" rather than an integral aspect of postgraduate education. It is therefore possible that the education needs of our current and future consultants are not being met.

\section{Existing strategies to meet non-clinical training needs} Pre-appointment strategies

To increase the opportunities for SpRs to gain relevant nonclinical experience, particularly in the area of management, a range of possible strategies can be identified from the literature, some involving existing initiatives. A number of authors have advocated an increase in the opportunities for SpRs to gain experience of the current clinical and nonclinical duties they would expect to perform as consultants. This approach is focused mainly on management experience. Mowat suggests that SpRs might use protected time for special interests to pursue experience of service management. ${ }^{17}$ Hooke also argues in favour increasing the level of exposure to management by suggesting SpRs undertake managerial attachments within trusts. ${ }^{13}$ Milton makes a more general suggestion for assisting the transition of SpRs (who are often shielded from administrative and managerial

\section{Learning points}

- Current and future consultants need non-clinical skills, such as management, leadership, and teaching skills.

- Non-clinical skills training, before and after appointment, is not standardised, reflected in doctors' concerns over the quality and quantity of training in this important area.

- There is a pressing need to address non-clinical skills training, particularly in light of the European Working Time Directive (EWTD) and new initiatives such as Modernising Medical Careers (MMC) (with accelerated progression to senior level).

- Parallels with general practice and higher professional education, along with ad hoc initiatives and evidence from medical education literature, provide insights into how training needs may be met at specialist registrar and consultant level.

- There is an urgent need to conduct empirical research on the needs of new consultants with a wider scope than local or specialty specific surveys. The impact of the EWTD and MMC on the preparedness of doctors for a consultant post must be carefully monitored.

pressures) to consultant grade and the non-clinical duties this will entail. ${ }^{18}$ He argues that final SpR post attachments should be tailored to better reflect the consultant role. ${ }^{18}$ This could be achieved by increasing the opportunities to gain management experience. The opportunity to attend relevant senior medical director or trust board meetings might also be useful. $^{18}$

Taking a slightly different approach, Warrington et al suggest that senior trainees attend quality assurance visits to training providers as a way of extending their experience of management and improving their skills in this area. ${ }^{19}$ They argue that participation in such visits can contribute to the development of management skills by offering the trainee an excellent opportunity to work with colleagues on a specific task, under pressure of time, while taking into account the needs of all parties involved. At the same time, participating in visits is seen as a way of improving teaching skills as it sharpens awareness of the factors contributing to an effective training scheme and offers insights into the commitment required to become a clinical tutor. Haddad and Creed and Loane and Barker make a number of recommendations for SpRs, including attendance at divisional meetings, shadowing hospital managers, gaining locum consultant experience, taking on some of a consultant's duties, and participating in SHO and SpR appointment committees. ${ }^{75}$ A further suggestion for increasing exposure to management issues and other non-clinical aspects of the consultant role is that doctors contribute to, and collaborate on projects on nonclinical aspects of healthcare provision, planning, and organisation. ${ }^{13} 15$

Alternative strategies entail doctors participating in more structured non-clinical training courses and events. Atkins and Ersser describe a multi-professional advanced practice course, a master of science in advanced healthcare practice developed in Oxford, UK, which is available to consultants and other senior healthcare professionals. ${ }^{20}$ The purpose of the course is to develop the range of skills needed (beyond clinical competencies) to become a leading health professional. The framework underpinning the course reflects attributes of professional practitioners working at an advanced level. These attributes are related to development 
and use of knowledge, personal and professional values, appreciation of wider critical context, cognitive processes, evaluative and investigative abilities, inter-professional working, and leading practice development. ${ }^{20}$

This approach to training provision does not necessarily have to entail the setting up of new courses locally. In New Zealand, senior psychiatric trainees have the opportunity to attend an annual, national forum (held over three days), which offers formal teaching of non-clinical skills in preparation for future management and leadership roles. Evaluations of the annual forums have suggested significant learning gains. ${ }^{21}$ Meanwhile, in the UK, Hooke proposes that doctors be given the opportunity to pursue a management qualification through established courses offered externally. ${ }^{13}$ However, attending specific training events is not essential. Initiatives such as the interactive, web based programme set up by the London Deanery (see http://www.healthcareskills. nhs.uk) exploit advances in distance learning and new technologies.

\section{Post-appointment strategies}

Once in post there seems to be fewer strategies for developing non-clinical skills. A number of authors advocate training courses for consultants. Houghton et al suggest educational courses and seminars be provided for new consultants, particularly in relation to management and leadership skills. ${ }^{22}$ This reflects the focus of the NHS Leadership Centre, which offers a portfolio of leadership development programmes. Grainger and Manek report on an induction course, which was created in Warwickshire and funded by the West Midlands Deanery, to develop the consultant workforce. $^{23}$ The course was developed in response to concerns that doctors lacked training and experience in areas relating to the kinds of management responsibilities they are expected to take on when appointed to a consultant post. The course was open to new consultants and GP principals and attendance required them to be released from their duties for a total of six days. This initiative seems to have met with some success, with the authors reporting positive feedback from questionnaires completed by both participants and course tutors. ${ }^{23}$

Continuing professional development (CPD) schemes, entailing a range of activities rather than specific training courses, have been described and advocated by other authors. Saidi and Weindling outline a CPD scheme in the UK for career grade paediatricians operated by the Royal College of Paediatrics and Child Health (RCPCH). ${ }^{24}$ The scheme has three key elements. These require participants to:

(1) develop individual personal development plans by identifying their own needs.

(2) record their CPD activities.

(3) divide these activities between those external to, and those internal to the trust.

Evaluation of the scheme consisted of nine focus groups with 49 paediatricians. Results suggested a positive impact on the clinical and professional practice of those participating in the scheme. Moreover, the use of professional development plans (PDPs) was regarded as useful for identifying educational needs. ${ }^{24}$ The advent of the appraisal process and the need for CPD may promulgate this approach to improving consultant education and training in non-clinical areas.

Mentoring strategies are also reported. Milton suggests that newly appointed consultants seek advice and support both informally and formally from more experienced colleagues. ${ }^{18}$ In particular, Hardern recommends that consultants consider their managerial and administrative responsibilities given that this is an area for which they are

\section{Summary of key recommendations}

- Dovetail training into personal development plans and the appraisal process

- Designate funding for non-clinical skills training courses (at trust or deanery level, or both)

- Maximise use of existing on-site resources such as local mentoring schemes

- Capitalise on local and national distance learning resources

- Increase opportunities for SpRs to access and acknowledge non-clinical skills education throughout their training

- Provide support for the new consultant entry scheme at deanery level by advising and supporting participating doctors on CPD, PDP, and mentorship.

likely to have received insufficient training. ${ }^{25}$ Mentoring systems for new consultants are not yet widespread, however the Royal College of Physicians (along with other colleges) and the Department of Health are currently developing a template for a system of consultant mentoring. ${ }^{26}$

\section{BARRIERS TO OVERCOME}

Resource provision is the main hindrance to non-clinical skills training for consultants. Two problems in particular relate to the provision of protected time for training and the relevance or "level" of that provision (which, in turn, is linked to the availability of appropriate expertise). To successfully undertake programmes of personal development, consultants need time away from their clinical duties. A UK survey of consultants and non-training grade anaesthetists, looking at their experiences of, and attitudes to continuing medical education, found that over one third of the 129 respondents claimed to have difficulties taking time off work to attend educational activities. ${ }^{27}$ The relevance of nonclinical training has also been raised as an issue by evaluations of training schemes. Participants might lose faith in training activities and regard them as unattractive, irrelevant, and of little use if they are not tailored to individuals nor pitched at the level of new consultants rather than junior doctors. ${ }^{24} 28$

\section{THE WAY FORWARD}

There is a need for a form of higher professional education for both newly qualified consultants and those intending to become consultants. This need will become increasingly

\section{Sources of information and useful contacts}

- NHS Leadership Centre - http://www. leadershipdevelopment.nhs.uk

- International Institute for Clinical Leadership-hittp:// www.wmdeanery.org

- Healthcare skills-hitp://www.healthcareskills.nhs.uk

- Royal College of Paediatrics and Child Health CPD scheme-http://www.rcpch.ac.uk

- Royal College of Physicians CPD scheme-http:// www.rcplondon.ac.uk

- The new consultant entry scheme-http://www.doh. gov.uk/iwl/newconsenrty.doc 
pressing as the EWTD comes into force, restricting time at work, while the new "run through" grades (resulting from Modernising Medical Careers) produce consultants who have spent less time in post-qualification training grades. How should we respond to this? We offer the following suggestions in light of our review of the literature:

(1) Several deaneries have developed a generic curriculum for the SpR grade to incorporate the known areas for which SpRs feel ill prepared. Some educational needs, however, do not become apparent or recognised until consultants are actually in post (for example, the need to acquire managerial and administrative skills). Training should therefore be dovetailed into personal development plans and the appraisal process so that these needs can be identified and addressed on an individual basis within a trust.

(2) The training needs of new consultants must be recognised and formally met via designated funding and the provision of courses either within trusts' educational/ induction programmes or via a wider deanery programme. However, acquisition of non-clinical skills should not be time limited in the way that GP HPE is currently.

(3) Maximum use should be made of on-site resources such as local mentoring schemes with trained mentors, and should form an integral part of the consultant's CPD programme.

(4) There is scope for SpRs and new consultants to capitalise on carefully evaluated "distance learning" resources, which exploit increasingly sophisticated new technologies, at both local and national level. Some of these may entail funding commitments where access or licence agreements are an issue.

(5) Greater opportunities should be afforded SpRs in acknowledging and accessing non-clinical skills education throughout their training rather than attendance at a management course after their last record of in-service training assessment.

(6) The new consultant entry scheme, which builds on the work of the London Deanery, is being rolled out nationally. The scheme offers SpRs with their CCST and non-consultant career grade doctors on the specialist register the opportunity to be placed in a substantive consultant post on a six months' fixed term contract. In doing so, the scheme will ease the transition to consultant grade for doctors. To ensure the scheme's success, it is imperative that deaneries effectively advise and support participating doctors on CPD, a structured personal development plan, and mentorship.

In short, systems need to be put into place now to ensure provision is available and appropriate for the less experienced consultants who will qualify under the radical changes envisaged in Modernising Medical Careers.

\section{CONCLUSION}

Senior doctors need specific training tailored to their individual needs and this is likely to include non-clinical skills, which historically have been poorly taught. The ethos of supportive protected time for education, prevalent during early training years, needs to continue as doctors progress to consultant level. There are opportunities to achieve this within the NHS, via higher education institutions, interactive programmes (such as web based, distance learning programmes), and local developments. A multi-professional strategy to mirror the initiatives launched for allied health professionals and senior professionals in external organisations may offer an appropriate framework within which to capitalise on these opportunities. However, commitment to this improvement strategy has resource implications, which individuals and organisations will have to address if patients are to continue to benefit from healthcare delivered by highly skilled consultants and the teams with which they work.

\section{QUESTIONS (TRUE (T)/FALSE (F); ANSWERS AT END OF REFERENCES)}

- Most UK deaneries offer management training courses to doctors at the beginning of their specialist training.

- Higher professional education (HPE) in general practice offers newly qualified GPs access to 20 days education during the first 12 months after completion of the VTS.

- Studies highlighted in this review suggest that SpRs are unaware of the non-clinical skills they will need at consultant level.

- The NHS Leadership Centre offers a portfolio of leadership development programmes.

- The new consultant entry scheme offers doctors looking for their first consultant post the opportunity to experience working in a consultant post on a fixed term basis.

\section{Authors' affiliations}

R Higgins, D Gallen, Leicestershire, Northamptonshire and Rutland Postgraduate Deanery, Leicester, UK

S Whiteman, Department of Postgraduate Medicine and Dentistry, University of Manchester, Manchester, UK

Funding: none.

Competing interests: none.

Ethics approval: ethics approval was not necessary for this work and, therefore, not sought.

\section{REFERENCES}

1 Department of Health. The NHS Plan-proposals for a new approach to the consultant contract. London: Department of Health, 2001.

2 Department of Health. Modernising medical careers - the response of the four UK health ministers to the consultation on unfinished business: proposals for reform of the senior house officer grade. London: Department of Health, 2003.

3 Talbot M. Good wine may need time to mature: a critique of accelerated higher specialist training. Evidence from cognitive neuroscience. Med Educ 2004;38:399-408.

4 Price AJ, Willett K. Optimising higher surgical training in trauma and orthopaedics. Bull R Coll Surg Engl 2003;85:78-81.

5 Stewart J, Bregazzi R, O'Halloran C. Accident and emergency medicine specialist registrars' perceptions of the "essential" aspects of a training placement. Learn Health Soc Care 2003;2:28-36.

6 Evans J, Goldacre MJ, Lambert TW. Views of junior doctors on the specialist registrar $(\mathrm{SpR})$ training scheme: qualitative study of medical graduates. Med Educ 2002;36:1122-30.

7 Haddad P, Creed F. Skills training for senior registrars. Psychiatr Bull R Coll Psychiatr 1996;20:391-4.

8 Smith LFP, Eve R, Crabtree R. Higher professional education for general practitioners: postal questionnaire survey. Br J Gen Pract 2000;50:288-92.

9 Peile E, Buckle G, Gallen D. Higher professional education for general practitioners. Oxford: Radcliffe Medical Press, 2003.

10 Hibble A. Report of the second Cambridge conference on higher professional education for general practice. Cambridge: Anglia Region, 1998.

11 Khera N, Stroobant J, Primhak RA, et al. Training the ideal hospital doctor: the specialist registrars' perspective. Med Educ 2001;35:957-66.

12 Gibson DR, Campbell RM. Promoting effective teaching and learning: hospital consultants identify their needs. Med Educ 2000;34:126-30.

13 Hooke R. Junior doctors should be given more opportunities to participate in management. BMJ http://bmi.bmijournals.com/cgi/content/full/325/ 7361/S63 (accessed Oct 2003).

14 Gould D, Kelly D, Goldstone L, et al. The changing training needs of clinical nurse managers: exploring issues for continuing professional development. Issues Innov Nurs Educ 2001;34:7-17.

15 Loane R, Barker A. Newly appointed consultants in old age psychiatry and the adequacy of higher training. Psychiatr Bull R Coll Psychiatr 1996;20:388-90.

16 Department of Health. Managing for excellence in the NHS. London: Department of Health, 2002.

17 Mowat D. Management training for the aspiring consultant. BMJ http:// bmi.bmijournals.com/cgi/content/full/325/7361/S61 (accessed Aug 2003).

18 Milton J. So who wants to be a consultant general psychiatrist. Psychiatr Bull R Coll Psychiatr 1998;22:345-7. 
19 Warrington J, Edmonstone YG, Strachan J. College approval visits - a perspective on trainee participation. Psychiatr Bull $R$ Coll Psychiatr 1996;20:348-50.

20 Atkins S, Ersser SJ. Education for advanced nursing practice: an evolving framework. Int J Nurs Stud 2000;37:523-33.

21 MacDonald J, Cole J. Trainee to trained: helping senior psychiatric trainees make the transition to consultant. Med Educ 2004;38:340-8.

22 Houghton A, Peters T, Bolton J. What do new consultants have to say? BMJ http://bmi.bmijournals.com/cgi/content/full/325/7372/S145a (accessed Aug 2003).

23 Grainger C, Manek N. Role rehearsal. Health Serv J 2002;1 12:26-7.

24 Saidi G, Weindling M. An evaluation of a national scheme for continuing professional development (CPD) for career grade doctors: the Royal College of Paediatrics and Child Health's programme for paediatricians evaluated by focus group methodology. Med Educ 2003;37:328-34.
25 Hardern R. Starting a new consultant post. BMJ http://bmi.bmijournals.com/ cgi/content/full/317/7165/S2-71635 (accessed Oct 2003).

26 Black C. The thoroughly modern consultant? Modernising consultant careers. Hosp Med 2003:64:196-7.

27 Heath KJ, Jones JG. Experiences and attitudes of consultant and nontraining grade anaesthetists to continuing medical education (CME). Anesthesiology 1998;53:461-7

28 Williams C, Sims A, Sensky T. Consultant Psychiatrists' opinions and experience of CPD. Psychiatr Bull R Coll Psychiatr 1998;22:348-50.

\section{ANSWERS}

1. F; 2. T; 3. F; 4. T; 5. T.

\section{Clinical Evidence - Call for contributors}

Clinical Evidence is a regularly updated evidence-based journal available worldwide both as a paper version and on the internet. Clinical Evidence needs to recruit a number of new contributors. Contributors are healthcare professionals or epidemiologists with experience in evidence-based medicine and the ability to write in a concise and structured way.

Areas for which we are currently seeking authors:

- Child health: nocturnal enuresis

- Eye disorders: bacterial conjunctivitis

- Male health: prostate cancer (metastatic)

- Women's health: pre-menstrual syndrome; pyelonephritis in non-pregnant women

However, we are always looking for others, so do not let this list discourage you.

Being a contributor involves:

- Selecting from a validated, screened search (performed by in-house Information Specialists) epidemiologically sound studies for inclusion.

- Documenting your decisions about which studies to include on an inclusion and exclusion form, which we keep on file.

- Writing the text to a highly structured template (about 1500-3000 words), using evidence from the final studies chosen, within 8-10 weeks of receiving the literature search.

- Working with Clinical Evidence editors to ensure that the final text meets epidemiological and style standards.

- Updating the text every six months using any new, sound evidence that becomes available. The Clinical Evidence in-house team will conduct the searches for contributors; your task is simply to filter out high quality studies and incorporate them in the existing text.

- To expand the topic to include a new question about once every 12-18 months.

If you would like to become a contributor for Clinical Evidence or require more information about what this involves please send your contact details and a copy of your CV, clearly stating the clinical area you are interested in, to Klara Brunnhuber (kbrunnhuber@ bmigroup.com).

\section{Call for peer reviewers}

Clinical Evidence also needs to recruit a number of new peer reviewers specifically with an interest in the clinical areas stated above, and also others related to general practice. Peer reviewers are healthcare professionals or epidemiologists with experience in evidence-based medicine. As a peer reviewer you would be asked for your views on the clinical relevance, validity, and accessibility of specific topics within the journal, and their usefulness to the intended audience (international generalists and healthcare professionals, possibly with limited statistical knowledge). Topics are usually 1500-3000 words in length and we would ask you to review between 2-5 topics per year. The peer review process takes place throughout the year, and our turnaround time for each review is ideally 10-14 days.

If you are interested in becoming a peer reviewer for Clinical Evidence, please complete the peer review questionnaire at www.clinicalevidence.com or contact Klara Brunnhuber (kbrunnhuber@bmigroup.com). 